\title{
Premonitory Phenomena of a Moderate Taiwan Earthquake
}

\author{
Kou-Cheng Chen, Jeen-Hwa Wang* \\ AND \\ YU-LIEN YEH \\ Institute of Earth Sciences \\ Academia Sinica, Taipei, Taiwan, R.O.C. \\ (Received 16 April 1990; revised 20 May 1990)
}

\begin{abstract}
An earthquake of $M_{D}=5.7$ occurred at Taipingshan, Ilan, Taiwan on May 10, 1983. A low seismicity zone appeared before the occurrence of the mainshock in the aftershock area. The epicentral pattern of aftershocks showed a significant correlation with an unexposed fault zone. The monthly frequency of events displayed abnormal seismicity both in the aftershock area and its neighborhood. This abnormal seismicity migrated somewhat from the outside area to the source area. $A$ bout one and a half years before the mainshock, the $b$ values increased markedly but then decreased before the major event. The duration ratio (DR) of the total coda waves duration time from a distant station compared to that at a closer station is also studied as an earthquake precursor. The DR values immediately decreased after the mainshock. An overestimation of total coda waves duration times for the close-in station might be due to a mixture of seismograms generated from the events which occurred in a small time interval and might result in this decrease. One hour after the mainshock, the DR values raised. This is interpreted to be a result of a large fracture density caused by the rapid increase of the number of $M_{D}>3$ events immediately after the mainshock.
\end{abstract}

\section{INTRODUCTION}

The Taiwan region is situated at the collision boundary between the Philippine Sea plate and the Eurasian plate, together with the opening of the Okinawa trough (Tsai et al., 1977; Tsai, 1986). Interactions here yield significant tectonic patterns and seismicity. Many moderate and large earthquakes occur frequently in this region. Detailed studies on the premonitory anomalies prior to a major earthquake are undoubtedly one of the major subjects of study in the region.

\footnotetext{
* Also at Institute of Geophysics, National Central University, Chungli, Taiwan, R.O.C.
} 
On May 10, 1983, a moderate earthquake occurred at Taipingshan, Ilan, Taiwan (Fig. 1). Its related parameters as determined by the Taiwan Telemetered Seismographic Network (TTSN) are:

Epicenter: $24^{\circ} 27.5^{\prime} \mathrm{N}$ and $121^{\circ} 30.4^{\prime} \mathrm{E}$,

Focal depth: $1.2 \mathrm{~km}$,

Original time: $00 h 15 \mathrm{~m} 03.8 \mathrm{~s}$ (UT),

Magnitude: $M_{D}=5.7$.

Chen and Wang (1984) studied the focal mechanisms and seismicity of this earthquake sequence in detail. It had normal faulting with a strike of $36^{\circ}$ NW and a dip of $40^{\circ}$ SW (Fig. 1). Wang and Chen (1985) reported a few seismological phenomena prior to the mainshock. In this study, we will report several different premonitory phenomena including the spatial patterns of the earthquakes, the monthly frequency of the events, temporal variations in the b-values, monthly cumulative energy, seismicity rates, and temporal variation in the duration ratios. The studied area is from $24^{\circ} 20^{\prime} \mathrm{N}$ to $24^{\circ} 40^{\prime} \mathrm{N}$ in latitude and from $121^{\circ} 20^{\prime} \mathrm{E}$ to $121^{\circ} 40^{\prime} \mathrm{E}$ in longitude. The seismological data used in this study were recorded by the TTSN. The magnitude scale used by the TTSN to quantify the earthquake size is the durational magnitude.

\section{SPATIAL PATTERNS OF THE EARTHQUAKES}

Fig. 1 shows the epicentral patterns of larger earthquakes for the background seismic activity from January 1973 to August 1981, foreshocks from September 1, 1982 to May 9, 1983 and aftershocks from May 10 to May 28, 1983. The criterion used to distinguish the three periods will be illustrated in the next section. Actually, there are two groups of foreshocks: the first one occurred southeast of the aftershock area in the period between September 1982 to April 1983 and the second one (called the immediate foreshocks) took place within the aftershock area four days before the occurrence of the mainshock. Fig. $2 \mathrm{a}$ shows the high seismicity in the area considered. Four days before the mainshock, numerous foreshocks (Fig. 2b) occured that were located in a small area depicted by the dashed line (Fig. 2a). The mainshock took place in the southern part of the foreshock area. Fig. 2c shows the outward expansion of the aftershocks from the foreshock area. A Y-shaped aftershock zone can be easily delineated and is shown by the solid line in Fig. 2a. From Fig. 2 we see that, a low seismicity zone coinciding with the aftershock area appeared before the occurrence of the earthquake sequence. Only a few earthquakes with $M_{D} \geq 3$ were located within this zone. The appearance of a quiescent zone prior to a large earthquake is commonly found (Ohtake, et al., 1977a, b; Wyss and Habermann, 1979; Mogi, 1979; Kanamori, 1981; Wyss, et al., 1981; Wyss, et al., 1983; McNally, 1983) and is usually regarded as a significant indication 


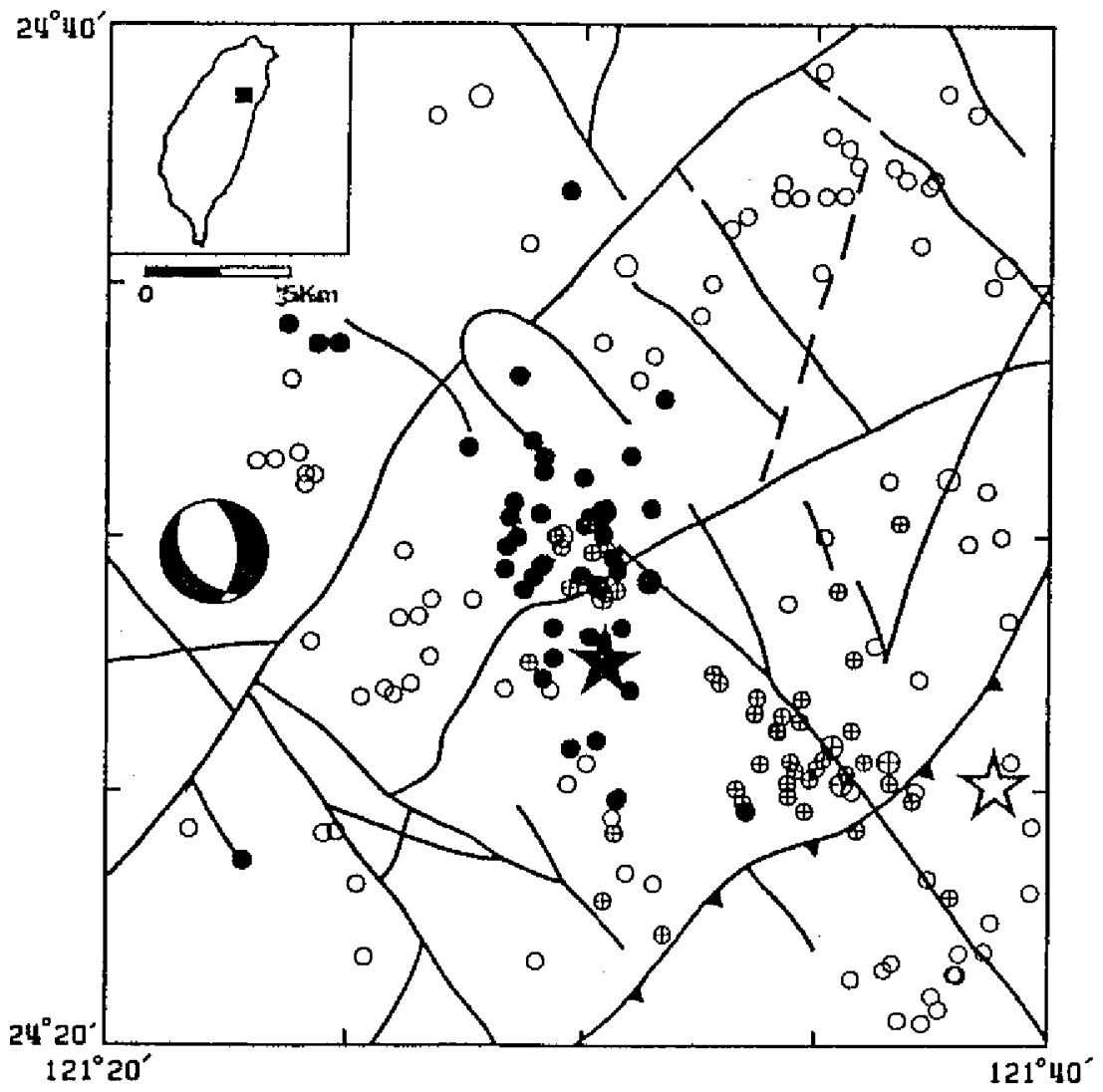

Fig. 1. Spatial distribution of larger earthquakes $\left(M_{D} \geq 3\right)$ for the background activity (open circles), foreshocks (hatched circles) and aftershocks (solid circles). Also shown on the map are fault traces delineated from radar images (MRSO, 1982). The open star represents the December 6, 1978 deep earthquake, while the solid star denotes the mainshock of the May 10, 1983 Taipingshan earthquake sequence.

for an impending large earthquake.

The space and time pattern of the earthquakes from May 6 to May 11, 1983 is particularly significant and is shown in Fig. 3. Most of the foreshocks were located in a small area. During the first two days, the foreshocks began to appear to the northwest of the mainshock area and then extended southeastward. On May 8, 1983 the seismicity of the foreshocks abruptly increased and migrated along in the NW-SE direction. The foreshocks took place within a smaller area to the northwest of the mainshock occured on May 9, 1983. The shocks that occurred immediately after the mainshock on May 10, 1983 were also located within a larger zone as were the foreshocks. Apparently, the aftershocks expanded northward from the foreshock zone. 


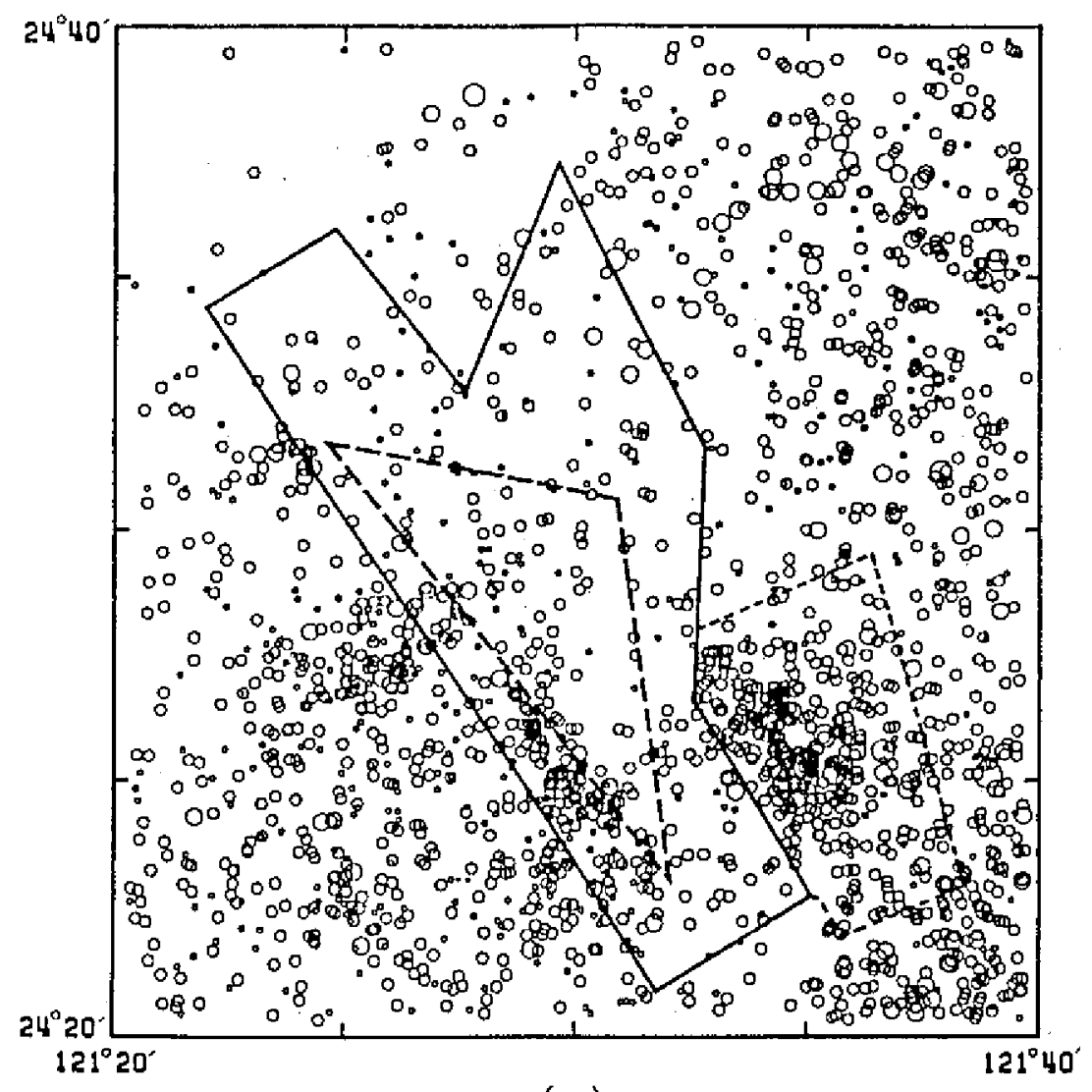

(a)

Fig. 2. (a) Spatial distribution of events with $M_{D} \geq 1$ from January 1973 to May 5, 1983, (b) foreshocks from May 6 to May 9, 1983, and (c) aftershocks from May 10 to May 28, 1983. The foreshock area and that aftershock area are depicted by the dashed line and the solid line in (a). Earthquakes that occurred in the period from September 1982 to April, 1983 are depicted by a dotted line. The star in (c) represents the epicenter of the mainshock.

The monthly frequency of earthquakes $\left(1 \leq M_{D}<6\right)$ occurring within the studied area in the period before 1984 is shown in Fig. 4a. Before May 1983, one event occured with $M_{D}=5.9$. It was located at a depth of $161 \mathrm{~km}$ and occured on December 6, 1978. This event took place approximately $15 \mathrm{~km}$ southeast of the Taipingshan earthquake. No foreshocks or aftershock releated to this deep event were located. Since the events of the Taipingshan earthquake sequence were located within the shallow crust, this deep earthquake is not considered to be related to the Taipingshan earthquake sequence.

The average monthly number of events from 1973 to 1982 was about 23 . At the end of 1980, seismicity increased remarkably. In September 1982, the high seismicity anomaly came out. Though the monthly frequency dropped 


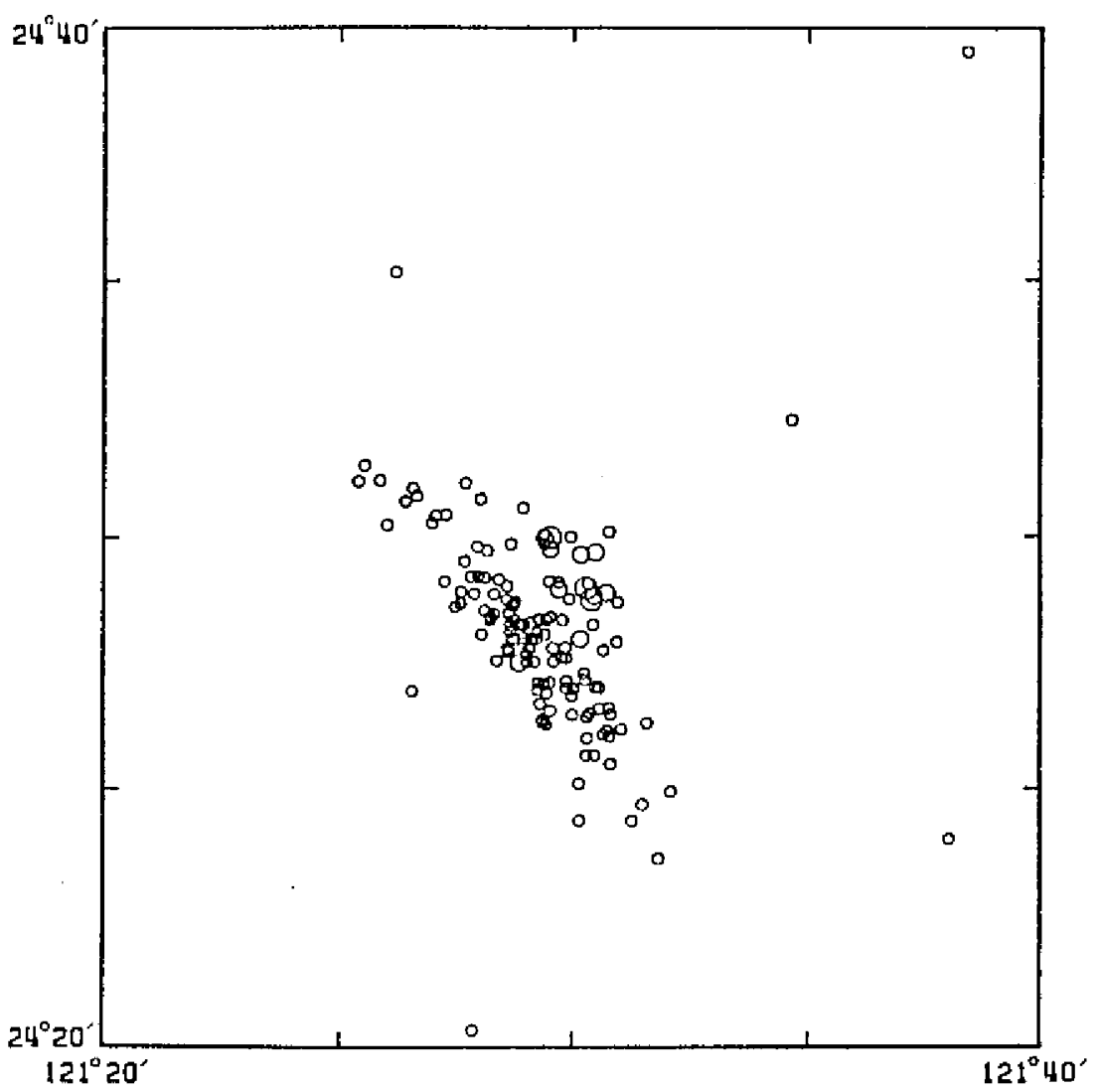

(b)

Fig. 2. (Continued)

again to a lower level, the average number of events was still higher than 23 . In May 1983, the seismic activity rose again. The criterion used to distinguish the background seismic activity and foreshocks as shown in the last section is based on the abnormal increase in the monthly frequency during September 1982. The events that took place before this month were regarded as background seismic activity, while those after this month and prior to the mainshock were considered as foreshocks.

To take a close look at the temporal variation of the earthquake occurrence, the daily frequency from April to August 1983 is plotted in Fig. $4 \mathrm{~b}$. As mentioned previously, the area considered was comparatively quiet during the period from the middle of April to May 5, 1983. An abrupt increase in seismic activity appeared four days before the mainshock. More than 220 aftershocks took place in the first 24 hours immediately after the mainshock. The aftershock activity increased rapidly both in number and in the magnitude of the earthquakes. 


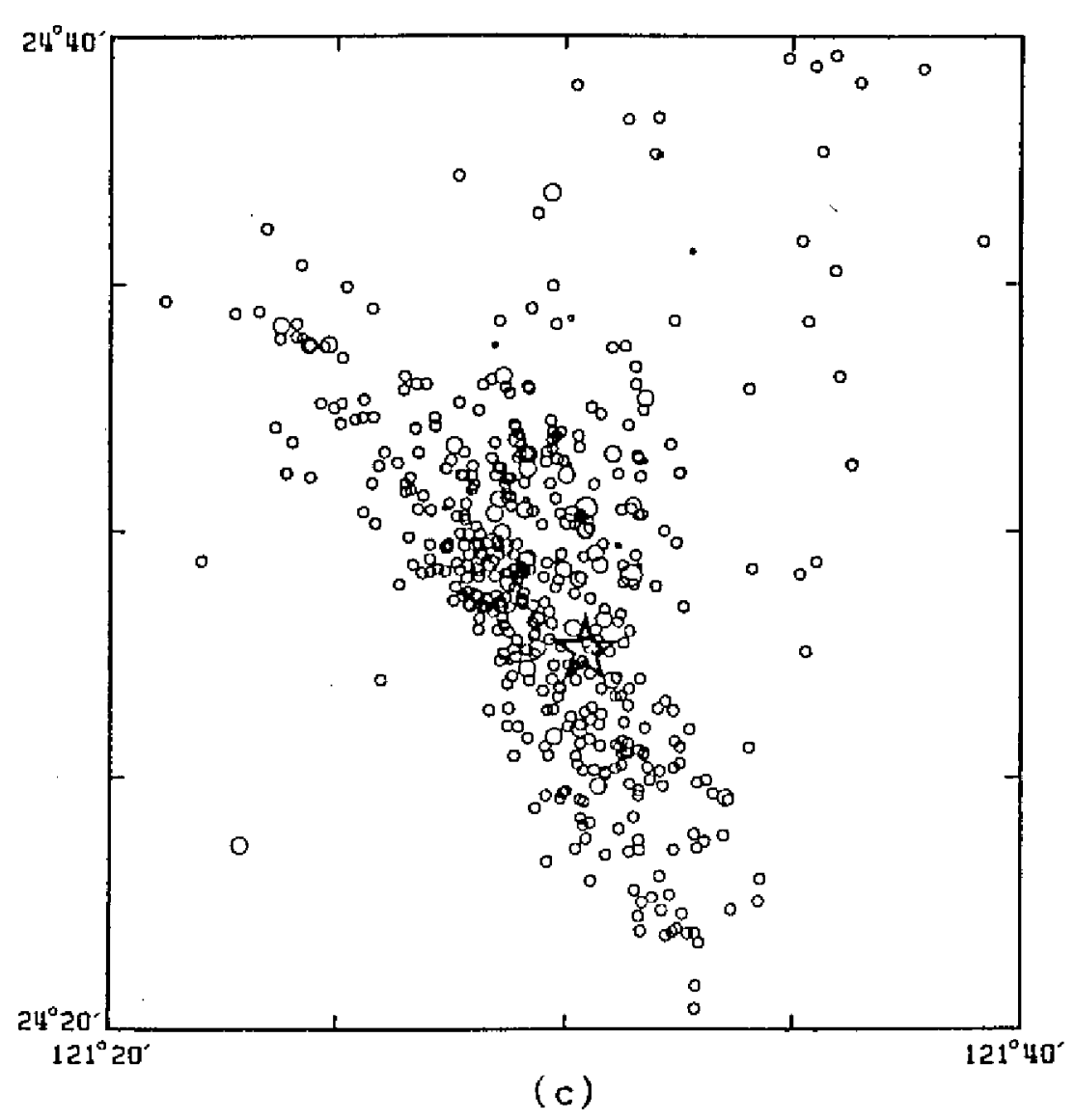

Fig. 2. (Continued)

The appearance of the quiescent zone mentioned previously suggests the need to study the premonitory phenomena within and outside this particular zone. The monthly frequency during 1973 to 1983 for the quiescent zone and its surroundings are shown in Figs. 5a and 5b; respectively. Remarkably, the two temporal variations are different. From 1973 to 1983 , seismic activity was lower in the quiescent zone than in the surrounding area. The peak monthly frequency appeared from September 1982 in the surrounding area. After that, the monthly frequency gradually reduced to the normal level. Almost simultaneously the monthly frequency in the quiescent zone began to increase. The observations show the migration of seismicity from the surrounding area to the quiescent zone.

In 1982, a group of events took place in a small area (shown by the dotted line in Fig. 2a) to the southeast of the source zone. Its activity gradually increased from June 1982, reaching a peak in September, and finally dropped to a level still higher than that of the background activity (see Fig. 4). This group of 

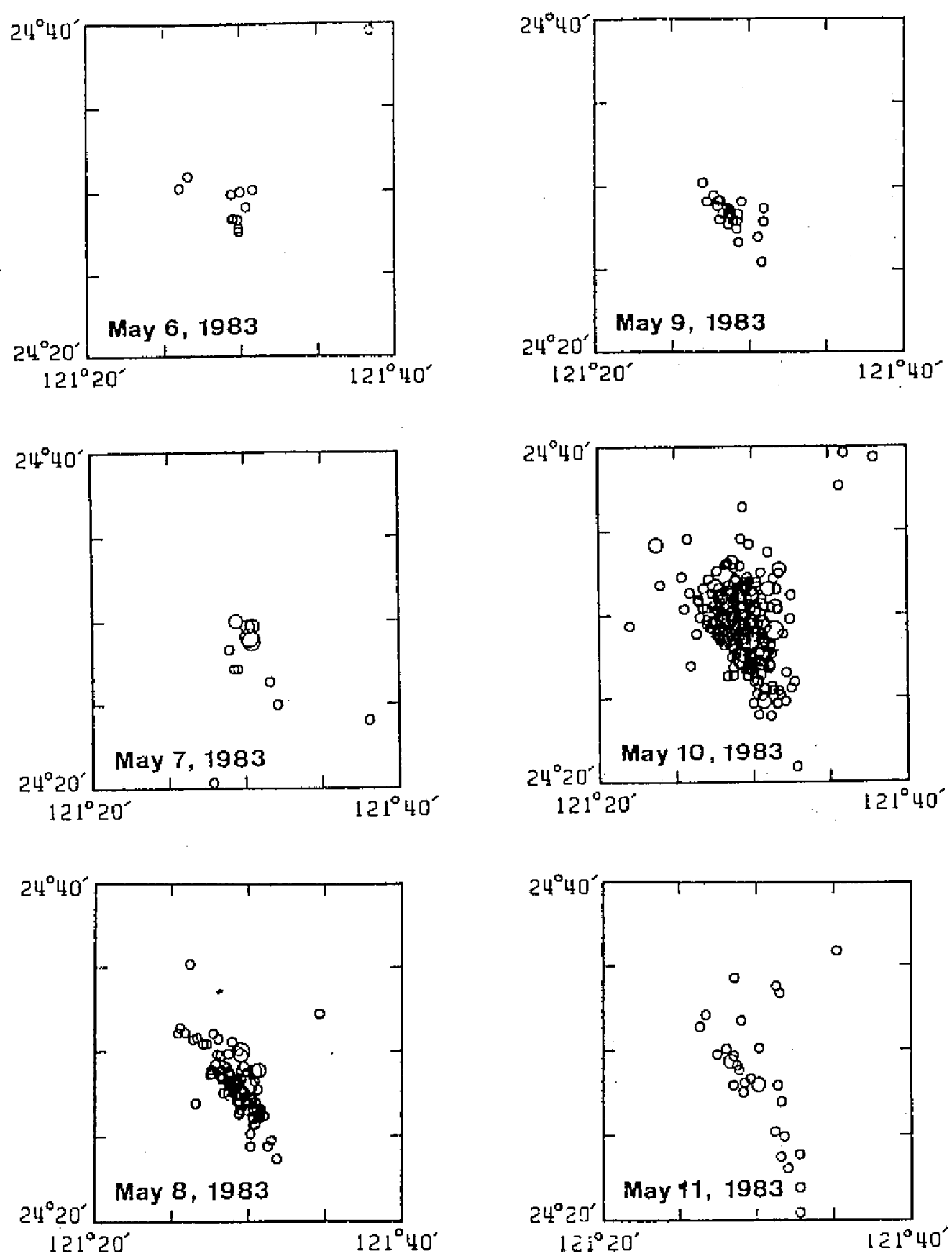

Fig. 3. The daily epicenters spatial patterns during May 6 to May 11, 1983 . The mainshock is denoted by a star.

events appeared about eight months before the mainshock of the Taipingshan earthquake sequence. During January 1973 to June 1982, a few somewhat 

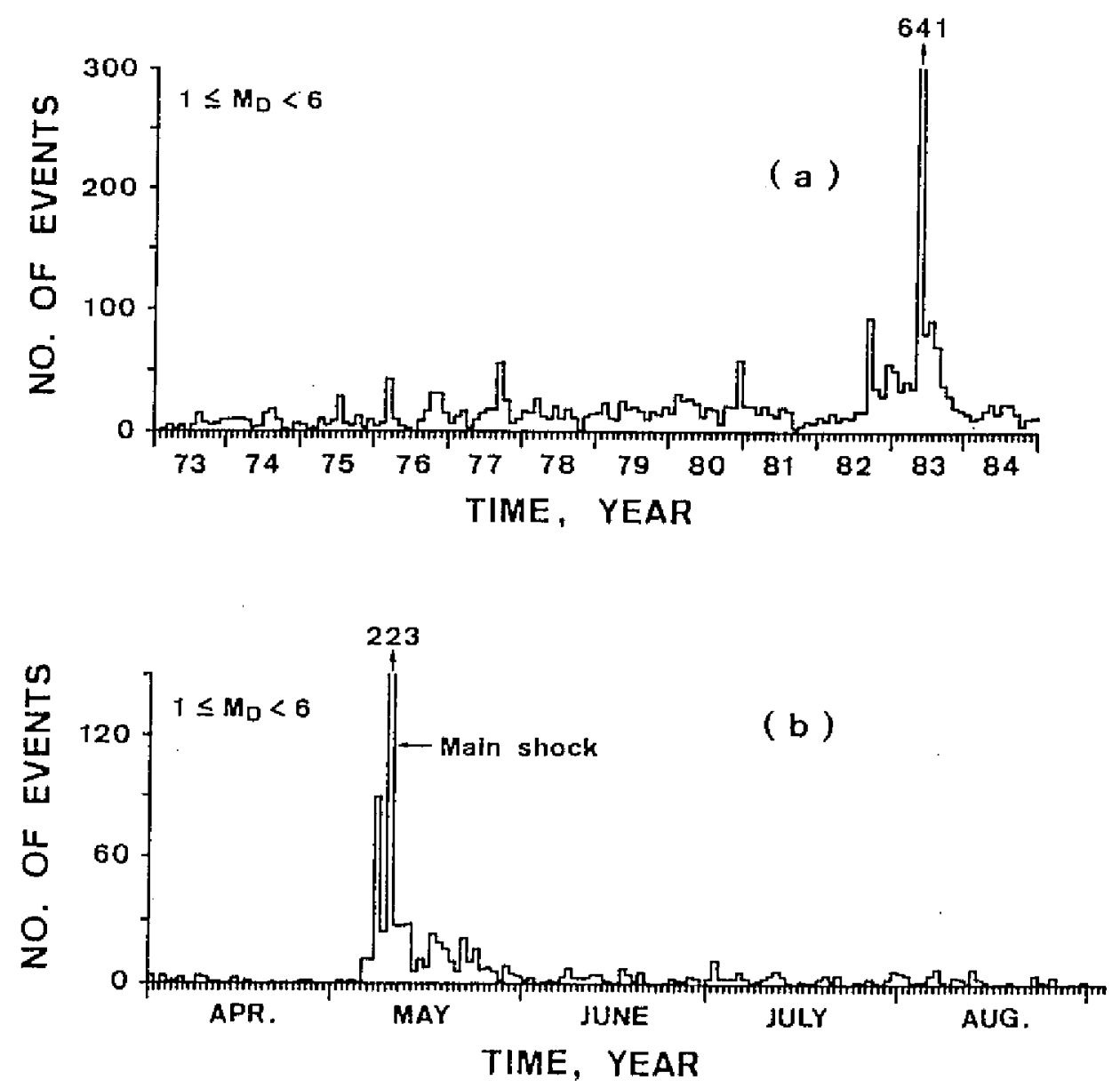

Fig. 4. The monthly frequency (a), and daily frequency (b) of earthquakes with $M_{D} \geq 1$ in the area considered.

higher activities were recognized. However, the number of events was smaller than that of the September 1982 group and their activities returned to the level of the background activity.

\section{SEISMICITY RATE AND SEISMIC ENERGY RELEASE}

The seismicity rate as represented by the cumulative number of earthquakes as a function of time is used to seek the possible change of seismicity before the Taipingshan earthquake. A low seismicity rate concerning the quiescent period prior to a large earthquake has been reported by many authors (Mogi, 1968; Engdahl and Kisslinger; 1977; Ohtake, et al., 1977a, b; Wyss and Habermann, 1979; Wyss, et al., 1981; Wyss, et al., 1983). The monthly cumulative 

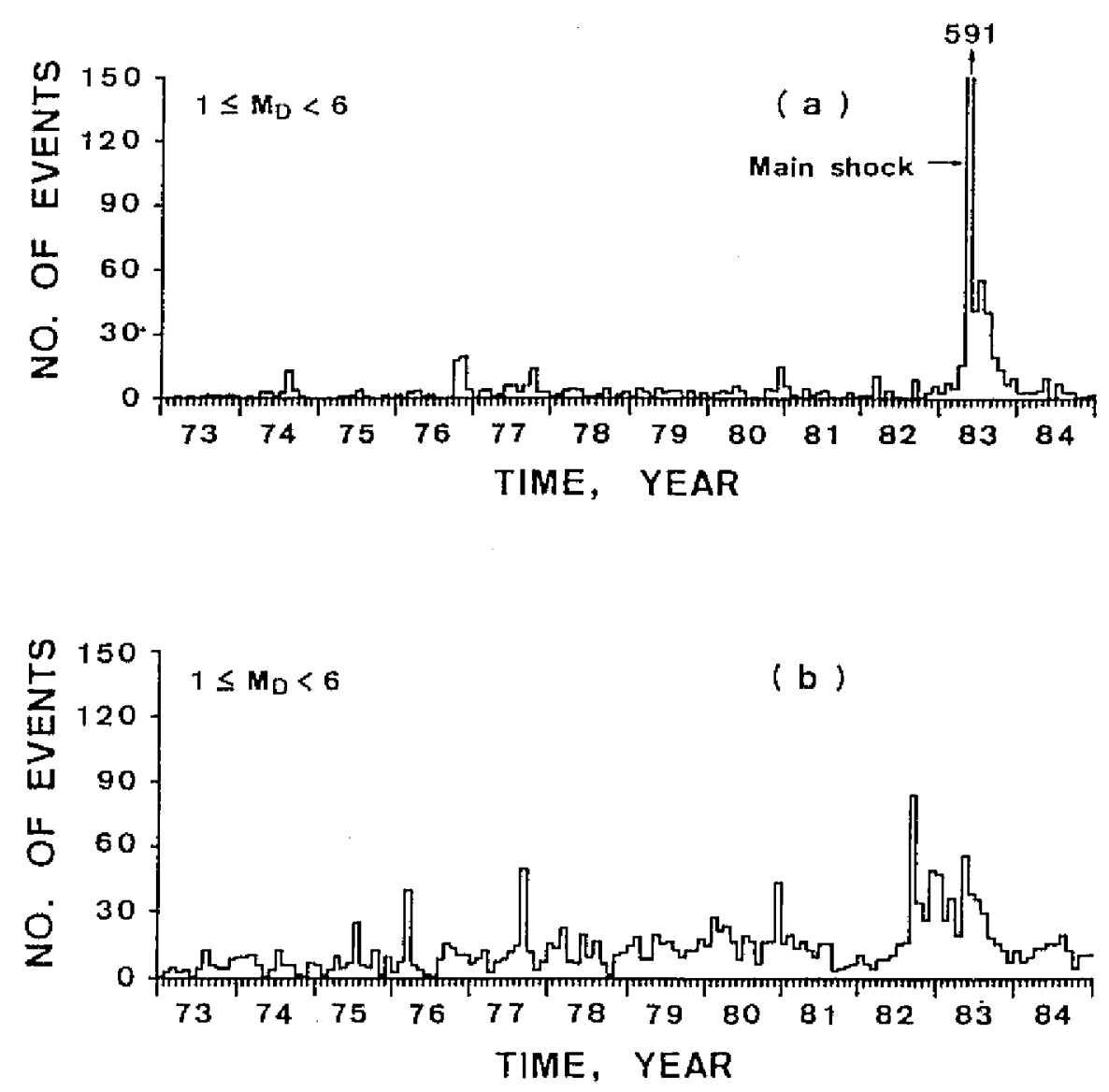

Fig. 5. The monthly frequency of events $\left(M_{D} \geq 1\right)$ in the source area (a), and its surrounding area (b).

number of earthquakes of $M_{D} \geq 1$ and $M_{D} \geq 3$ for the whole area considered is shown in Fig. 6a for the time period between 1973 to 1984. The total number of events in this sample is approximately 3200 . Before the Taipingshan earthquake sequence, the seismic activity with $M_{D} \geq 1$ is characterized by different seismicity rates for three time intervals. Before 1976, the lowest seismicity rate of the entire period might be due to the low detection capability of the TTSN because of the insufficiency of seismographic stations (Wang, et $\left.a l_{r}, 1986\right)$. However, the number of stations increased rapidly during 1973 to 1976 and then has been almost constant since 1976. The seismicity rate was remarkably stable over seven years from January 1976 to September 1982. This seismicity rate could be considered as the background seismicity rate. On the other hand, the recorded earthquakes with a magnitude greater than 3 has been completed because the seismicity rate is fairly constant from late 1973 to September 1982 (Fig. 6a). The seismicity rates for the two data sets of events 
with $M_{D} \geq 1$ and $M_{D} \geq 3$ significantly increased about eight months before the Taipinshan earthquake. This abnormal phenomenon might be a precursor to this earthquake.
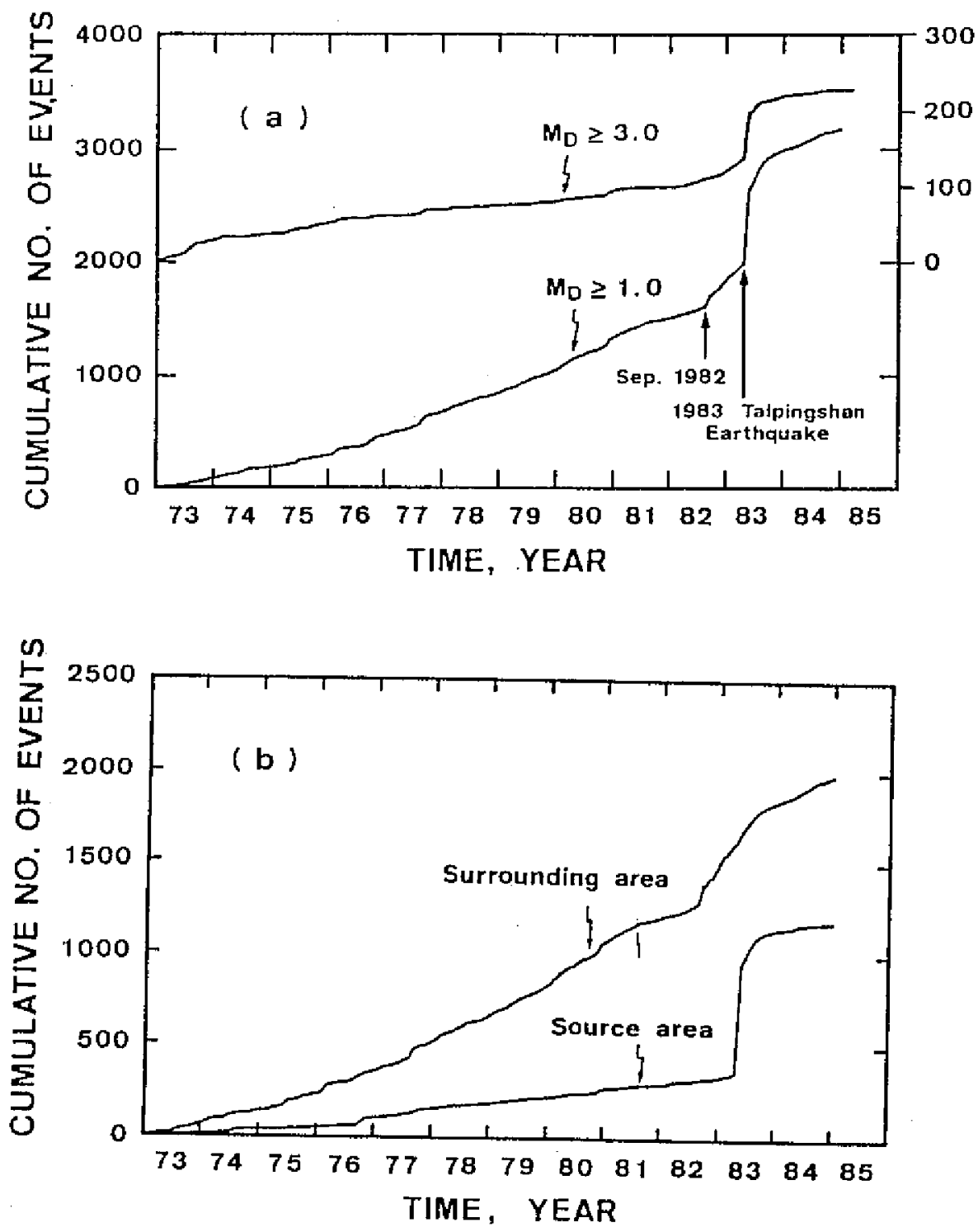

Fig. 6. (a) Monthly cumulative number of earthquakes for the area considered. The scale at the right-hand side is valid for the curve representing earthquakes with $M_{D} \geq 3$. (b) Monthly cumulative number of earthquakes for the surrounding area (upper solid line) and the source area (lower solid line).

For further study, the variations of the monthly cumulative number of earthquakes with $M_{D} \geq 1$ for the source area and the surrounding area are shown in 
Fig. 6b. In the source area, a constant seismicity rate of about 4 events/month appeared during January 1976 to April 1983. An abrupt increase in the number of immediate foreshocks and aftershocks changed the seismicity rate remarkably in May 1983. After June 1983, however, the seismicity rate of the source area returned to the normal value. From January 1976 to August 1982, a seismicity rate about three times larger than that of the source area was reported in the surrounding area. Of course the seismicity rate of the surrounding area was not constant, but varied around the average value. From August 1982 to June 1983, a seismicity rate about three times larger than the normal value appeared in spite of the occurrence of Taipingshan earthquake sequence in May 1983. However, after Jur:e 1983, the seismicity rate of the surrounding area recovered its normal value for the period from January 1976 to August 1982. Consequently, the intermediate-term precursory seismic activity appeared in the surrounding area about eight months before the mainshock; while the short-term precursory seismic activity described in the previous section appeared in the source area about four days before the mainshock.

The cumulative seismic energy released by the 3200 earthquakes occuring from 1973 to 1984 for the area considered is shown in Fig. 7. The seismic energy is estimated by

$$
\log E=11.8+1.50 M_{L}
$$

(Gutenberg and Richter, 1956). In Equation (1), $M_{L}$ is the local magnitude of the earthquake. For the TTSN routine work, the signal duration magnitude is used to quantify the size of the earthquake. Yeh and Hsu (1983) reported the $M_{L}-M_{D}$ relation for the Taiwan area in the following form:

$$
M_{L}=1.04+0.94 M_{D}
$$

The total cumulative seismic energy for the area considered during the 10 years before the Taipingshan earthquake is about $0.5 \times 10^{22} \mathrm{ergs}$, which corresponds roughly to a large event of $M_{D}=5.9$ or $M_{L}=6.6$. There are two conspicuous jumps in the time series of the cumulative seismic energy. The first jump corresponds to the occurrence of the deep December 6, 1978 earthquake, whose magnitude was larger than that of the May 10, 1983 earthquake. On the other hand, the size of the May 10, 1983 though smaller, was preceded and followed by many small shocks. Hence, a jump in the temporal variation of cumulative number of events and cumulative seismic energy are expected.

\section{TEMPORAL VARIATION IN b-VALUES}

The b-value in the Gutenberg and Richter's magnitude-frequency relation (Gutenber and Richter, 1944):

$$
\log N(M)=a-b M
$$




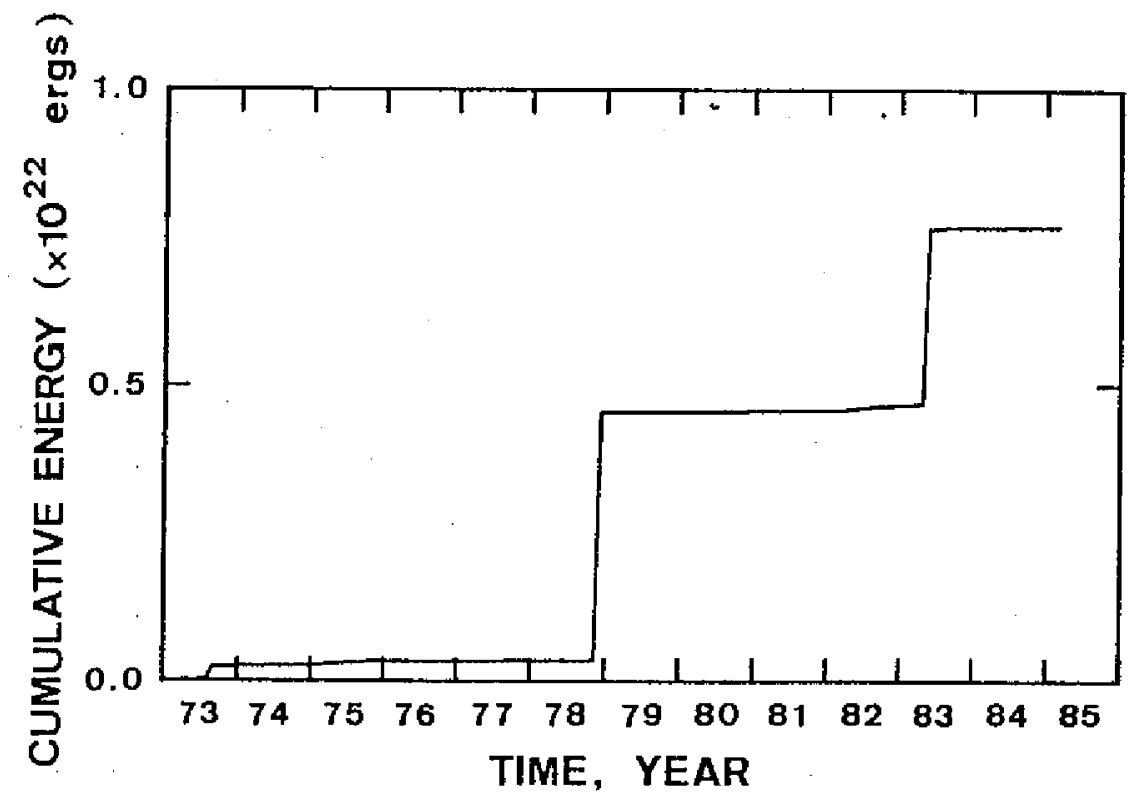

Fig. 7. Monthly cumulative seismic energy release for earthquakes with $M_{D} \geq 1$.

corresponds to the degree of nonuniformity structure and the tectonic conditions (Miyamura, 1962; Mogi, 1967). From laboratory studies of rock deformation, Scholz (1968) found that changes in b-value are inversely related to changes in stress. Temporal variation in b-value may thus be useful in monitoring the earthquake preparatoty process. In fact, many precursory decreases in b-value prior to a major earthquake have been found (e.g., Hasegawa et al., 1975; Li et al., 1978; Ishida and Ohtake, 1984).

Here, we attempt to estimate the yearly variation in $b$-values for the aftershock area, the surrounding area, and the entire area (Fig. 7). The magnitude range and standard deviation (SD) for each b-value are shown in Table 1. Essentially, the standard deviation is quite small except that for 1978, denoted by an open circle in Fig. 7. This large standard deviation is due to the small number of data. The average b-value (1.13) for the time interval from 1973 to 1983 and the b-value (0.99) for the foreshocks as estimated by Chen and Wang (1984) are also shown in Fig. 8. It is noted that the annual b-values vary around the average one. The annual $b$-values variation for the whole area is similar to that of the surrounding area rather than that of the aftershock area.

For the whole area considered $((\mathrm{a}+\mathrm{b})$ in Fig. 7$)$ and the surrounding area ((b) in Fig. 8), the b-values gradually increased from 1978 and reached its peak in 1981, and then decreased. The mainshock occurred in the time interval when the b-values reduced. On the other hand, in the aftershock area a small b-value 


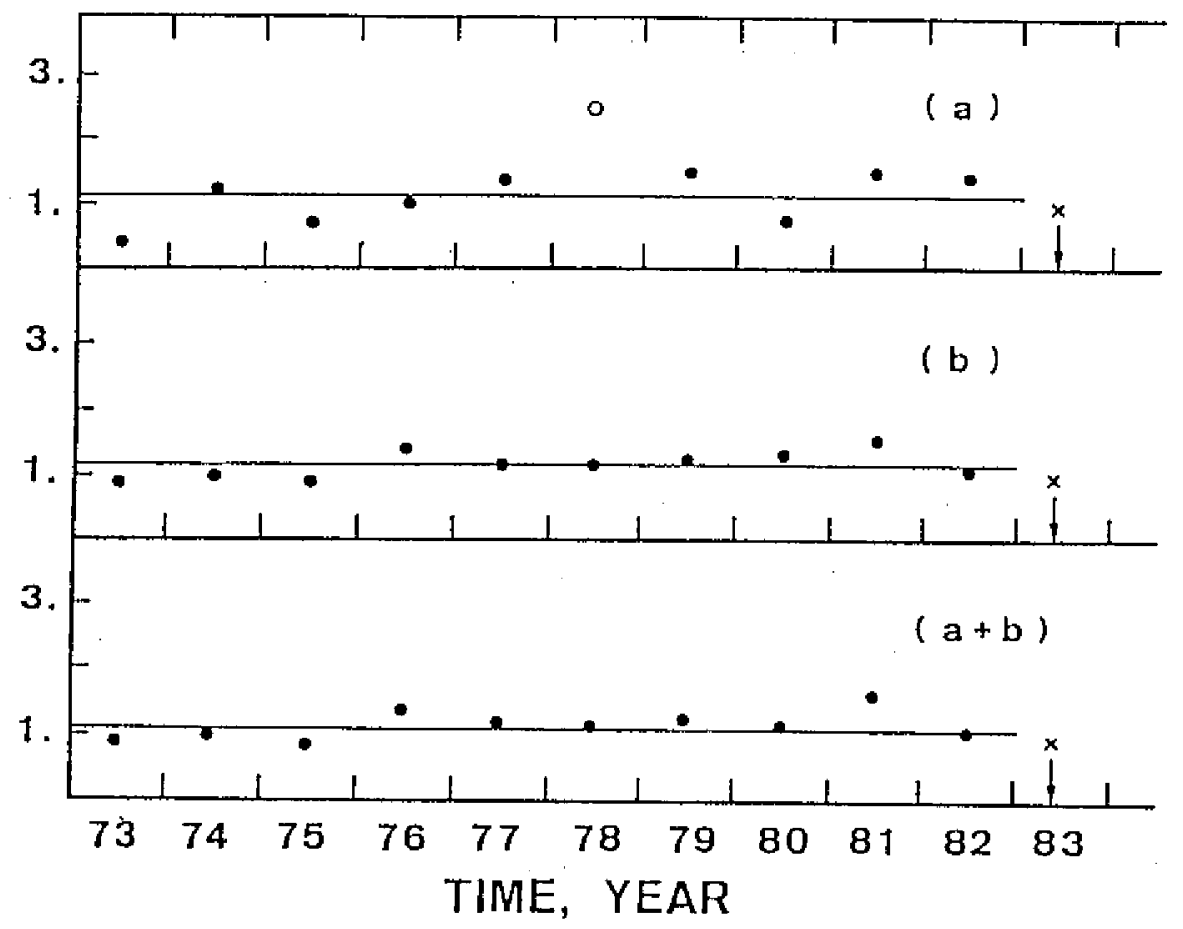

Fig. 8. The annual variation in b-values for the source area (a), the surrounding area $(b)$, and the whole area $(a+b)$. The line parallel to the time axis shows the average b-value (1.13) for the period of January 1973 to May 5, 1983. The cross shows the b-value (0.99) of the second group of foreshocks and the arrow represents the time when the mainshock occurred. The open circle in (a) denotes the b-value with high standard deviation (from Wang and Chen, 1985).

appeared in 1980 (see (a) in Fig. 7) but from 1981 to 1982, the b-values were slightly larger than average. The b-value for the aftershock area is remarkably smaller than the long-term average value.

\section{TEMPORAL VARIATION IN DURATION RATIO}

Sato (1977) suggested that coda waves are mainly affected by inhomogeneity in an ellipsoidal region with the epicenter and station site as the two foci. The inhomogeneity between the epicenter and the two stations determines the coda waves at the two stations. The different inhomogeneity in the region between the epicenter and the two stations would generate different coda waves recorded at the two stations. The change of inhomogeneity due to fracturing before and after the mainshock should be confined to the source area and its vicinity ( the effective fracture region). Coda waves recorded at the nearby station would sample a larger percentage of inhomogeneity within the effective fracture region. than those at the distant one, in their respective ellipsoids. One may expect that coda waves at the nearby station obtain stronger attenuation effects and have 
Table 1. The b-values and their standard deviations (SD) for the source area (a), the surrounding area (b), and the whole area (c). The magnitude range for the estimation of the $b$ value for each year is shown in paraenthesis (from Wang and Chen, 1985).

Time

Arca (a)

Area $(a+b)$

Area (b)

b $\quad \mathrm{SD} \quad \mathrm{M}$

b $\quad$ SD $\quad M$

b $\quad S D \quad M$

1973

$0.429 \quad 0.144 \quad 2.0-3.5$

$\begin{array}{lll}0.938 & 0.023 & 2.5-4.0\end{array}$

$0.930 \quad 0.028 \quad 2.5-4.0$

1974

$\begin{array}{lll}1.263 & 0.161 & 2.0-2.8\end{array}$

$0.979 \quad 0.008 \quad 2.0-3.3$

$0.989 \quad 0.004 \quad 2.0-3.3$

1975

$\begin{array}{lll}0.749 & 0.685 & 2.0-3.3\end{array}$

$0.902 \quad 0.023 \quad 2.0-4.1$

$0.888 \quad 0.030 \quad 2.0-4.1$

1976

$\begin{array}{lll}1.023 & 0.011 \quad 2.0-3.0\end{array}$

$1.399 \quad 0.196 \quad 2.0-3.2$

$1.3520 .169 \quad 2.0-3.2$

1977

$\begin{array}{lll}1.374 & 0.263 & 2.0-2.7\end{array}$

$\begin{array}{lll}1.207 & 0.088 & 2.0-3.3\end{array}$

$1.134 \quad 0.055 \quad 2.0-3.3$

1978

$2.499 \quad 2.828 \quad 2.0-2.3$

$1.169 \quad 0.065 \quad 2.0-3.5$

$\begin{array}{lll}1.126 & 0.047 \quad 2.0-3.5\end{array}$

1979

$1.469 \quad 0.596 \quad 1.9-2.2$

$\begin{array}{lll}1.270 & 0.113 & 2.0-3.4\end{array}$

$\begin{array}{lll}1.226 & 0.093 & 2.0-3.4\end{array}$

1980

$\begin{array}{lll}0.765 & 0.076 & 2.0-3.4\end{array}$

$\begin{array}{lll}1.161 & 0.057 & 2.0-3.6\end{array}$

$1.286 \quad 0.111 \quad 2.0-3.6$

1981

$1.482 \quad 0.396 \quad 2.0-2.6$

1.555. $0.275 \quad 2.0-3.3$

$1.492 \quad 0.238 \quad 2.0-3.3$

1982

$\begin{array}{lll}1.363 & 0.232 & 2.0-2.8\end{array}$

$1.074 \quad 0.023 \quad 2.1-4.1$

$1.044 \quad 0.013 \quad 2.0-4.1$

shorter duration times than those at the distant ones. Wang (1988) developed a simple method to estimate the change of coda waves before and after the mainshock. The comparison of code waves attenuation for the distant and nearby stations could be indicated by a quantity defined as the duration ratio (DR):

$$
\text { Duration Ratio }=T d s / T n s
$$

In equation (4), Tds and Tns are the total duration times from the original times of the event to the end of coda waves recorded at the distant and nearby stations, respectively.

Before the Taipingshan earthquake, only four distant stations (TWG, TWM1 , TWL, and TWO1) and one nearby station (TWD) had the same gain with $72 \mathrm{~dB}$ (Fig. 8). Hence, the seismograms from these five stations are used in this study. Fig. 9 shows the temporal variation of the duration ratios for the May 10, 1983 Taipingshan earthquake sequence. Although the data points show some scatter, four time intervals with similar duration ratios can be delineated. 


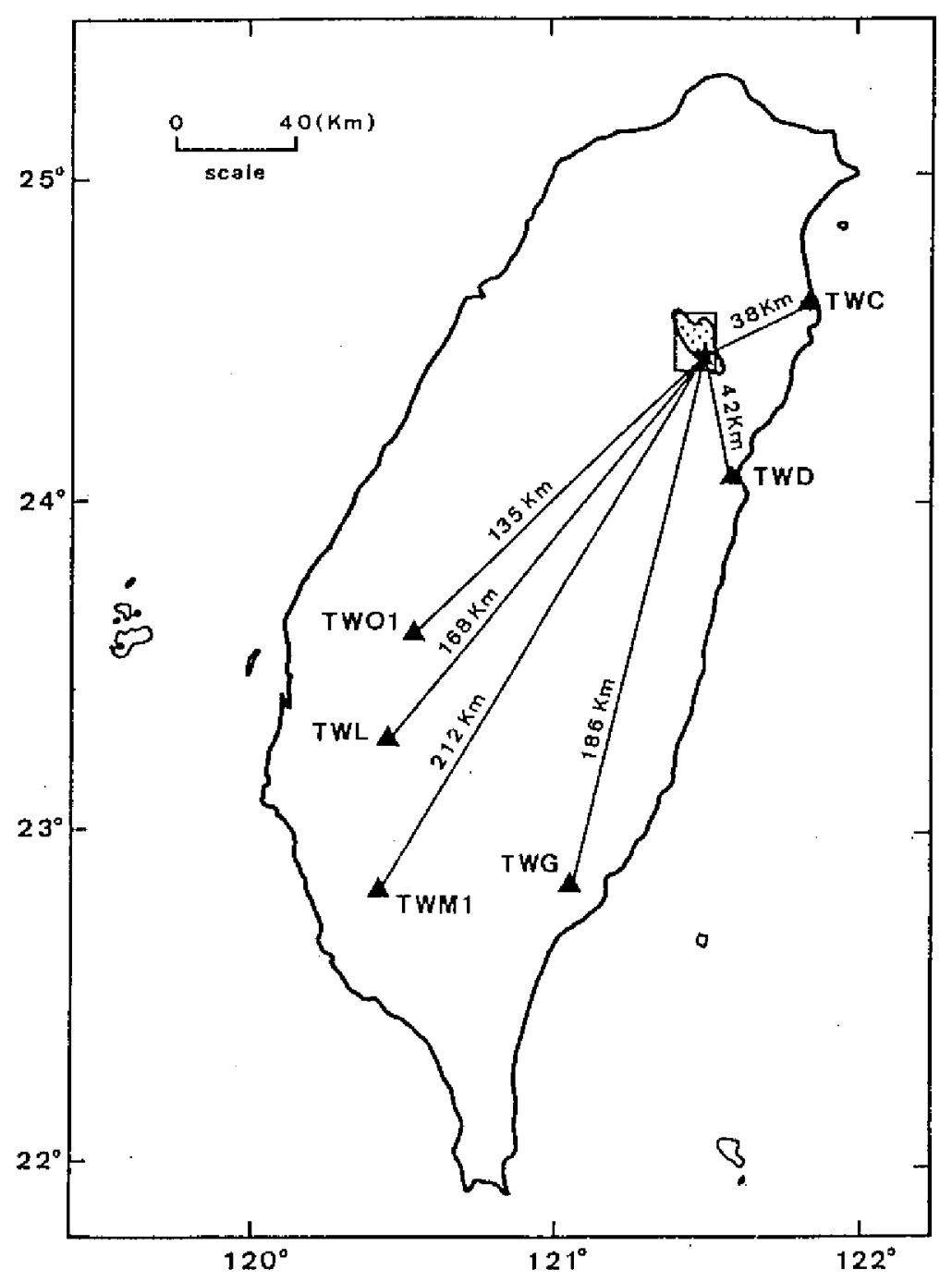

Fig. 9. Map shows the stations used (triangles), the mainshock epicenter (star), the source area (hatched area), and the distances from the stations to the mainshock epicenter (from Wang, 1988).

The means of the duration ratios and their standard errors (at $95 \%$ confidence) for the four time intervals are shown by solid lines and dotted lines, respectively. The DR values of the four time intervals are $1.036 \pm 0.142,1.396 \pm 0.184$, $0.912 \pm 0.138$ and $1.146 \pm 0.134$, respectively. The $\mathrm{DR}$ values remarkably increased from the first to second time intervals two days before the mainshocks, decreased in the third time interval one hour after the mainshock and increased again to a value slight larger than that in the first time interval. 


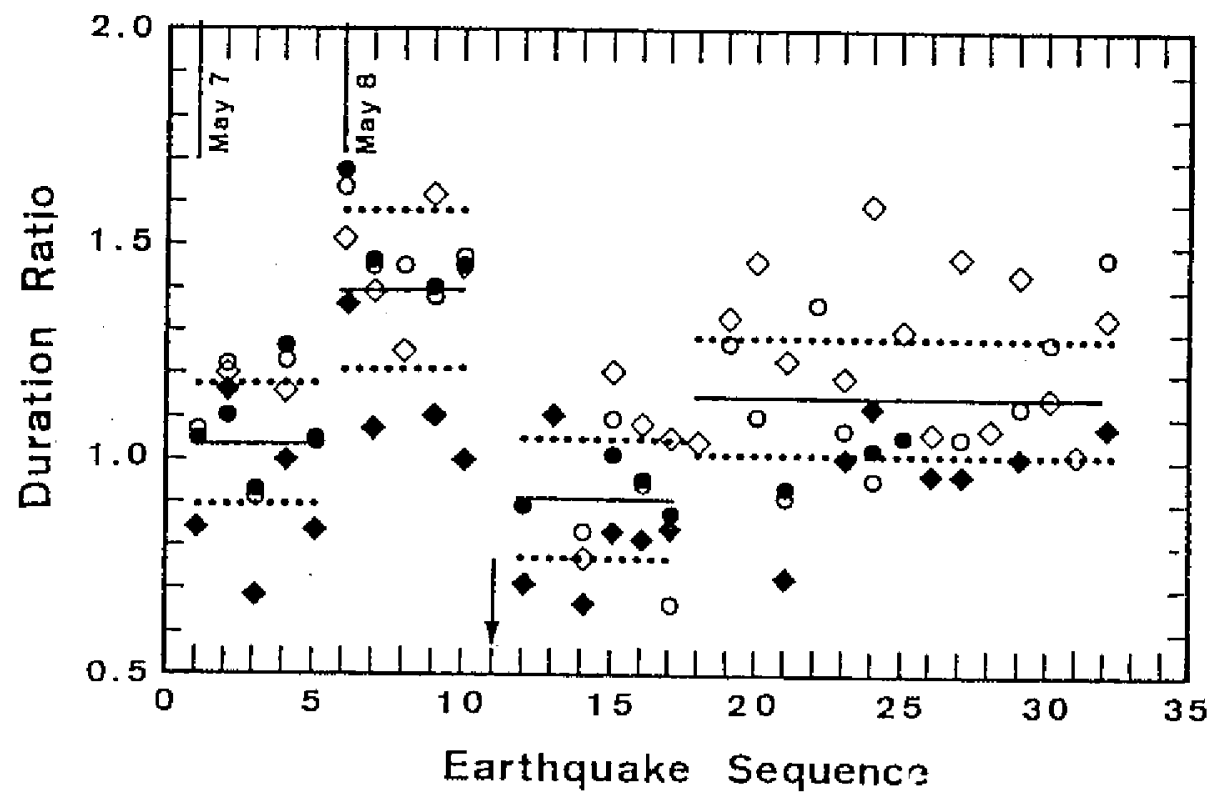

Fig. 10. Time variations in the duration ratios: solid diamonds for TWO1/TWD ; open diamonds for TWL/TWD; open circles for TWG/TWD; solid circles for TWM1/TWD. The time coordinates are plotted in the order of earthquakes. The arrow denotes the time of the mainshock. The solid and dotted lines display the average values and standard errors of duration ratios in four time intervals (from Wang, 1988).

\section{DISCUSSION AND CONCLUSIONS}

The quiescent zone before the 1983 Taipingshan earthquake sequence may be useful as an indicatior for the long-term precursor of a major earthquake. Only a few events with $M_{D} \geq 3$ occurred within the source zone in the years preceding the mainshock, while the region outside the source zone was more active. The appearance of a quiescent zone in the aftershock area (Fig. 2) and the space-time patterns of immediate foreshocks and aftershocks (Fig. 3) would qualitatively indicate the stress situation in the area considered. The fracture model suggested by Kanamori (1981) seems able to interpret the observations. The whole earthquake sequence as shown in Fig. 7 can be divided into four periods: the first one before September 1982, the second one from September 1982 to April 1983, the third one from approximately the middle of April 1983 to May 5, 1983, and the fourth one starting from May 6, 1983. The first period might, indicte be in this situation that the loading stress for the area studied was small, hence seismic activity was low. When the loading stress approached or immediately passed the average strength of the subfaults within the surrounding area, numerous shocks, (i.e. the first group of foreshocks) were 
stirred, thus leading to the second period. A similar process can also explain the fourth interval including the second group of foreshocks, the mainshock, and the aftershocks in the aftershock area. The third interval in this case was very short. One possible reason is the small difference between the average strength within the asperity and the surrounding area, so that the loading stress could easily reach the average stress of the asperity.

The cumulative number of events for the area considered shows a fairly constant background seismicity rate taken over several years. Although the cumulative number of events does not show the seismicity quiescence, the relatively high rate of seismicity which appeared eight months before the Taipingshan earthquake may be a significant indication as a medium-term precursor of a major earthquake. Rikitake (1979) suggested that the relationship between the precursor time $T$ measured in days and the magnitude $M$ of a major earthquake is given by

$$
\log T=0.60 M-1.01
$$

The values of $T$ and $M$ for the present study are 251 days and 5.7 respectively and seem to fit this relationship. Besides, the annual variation in b-values also shows abnormal phenomenon. For the surrounding area as well as the entire area, $b$ values increased somewhat gradually from 1978 reaching a peak in 1981 and then decreasing. The mainshock occurred in the period of reducted $b$ values.

An increase in seismic activity four days before the Taipingshan earthquake. may be particularly significant as a short-term precursor of a major earthquake. Besides, variation of b-values for background activity, foreshocks, and aftershocks show that the b-value of the foreshocks is less than that of the background activity and aftershocks. The fact that the b-value of the foreshocks is smaller than that of the aftershocks is quite a common phenomenon with large earthquakes (Ishida and Ohtake, 1984; Mezcua et al., 1984). The durational ratios obtained from the foreshocks also show a value increase two days before the mainshock. This phenomenon may be due to increased inhomogeneity within the effected rupture region.

The duration ratios increased remarkably from the first time interval to the second one (Fig. 10), possibly indicating that crustal inhomogeneity between the epicenters and the nearby station had become larger than those between the epicenters and the distant ones in the second time interval. Since coda waves recorded at the nearby station would sample more of the fracture region than those at the distant ones, shorter durational times are resulted for the former than the latter. Wang (1988) indicated that in the second time interval, the increase of the DR values was due to the abrupt occurrence of many largersize earthquakes in the source area. Wang et al. (1989) found a significant drop of coda $Q$ immediately after the mainshock for the Hualien earthquake of 
1986 in eastern Taiwan. The two observations may indicate either an increase of the degree of fracture or the enlargement of the fracture zone in the source area. The duration ratios decreased in the third time interval, one hour after the mainshock. High seismicity appeared in this time interval, since a main event is usually followed by several micro-events with different origin times, thus causing the mixture of their seismograms at the nearby station (TWD). On the other hand, most of such micro-events following the main one could not be detected at the distant stations. At the nearby station, the total duration time measured from the onset of the first event to the end of the last event is incorrectly used as the duration time of the first one, whose total duration time should be shorter than the measured one. Hence, the overestimated total duration times at the nearby station decreased the duration ratio in the third time interval. In the forth time interval, the duration ratios increased again. The earthquakes in this time interval expanded to include a wider region including the foreshock area. The occurrence of earthquakes could produce a large inhomogeneity within the effective fracture region and might account for the larger duration ratios in the forth time interval. Compared with the second time interval, however, the duration ratios in the forth time interval are lower. This might be due to the physical states, including the inhornogenity of the effective fracture region, beginning to recover to the same as those before the foreshocks.

In summary, the coincidence of the observed anomalies and the rupture zone of the 1983 Taipingshan earthquake strongly suggest that the anomalies are real and associated with the preparation process for the mainshock. However, no clear precursory phenomenon was found for the December 6, 1978 earthquake whose location is approximately $15 \mathrm{~km}$ southeast to the Taipingshan earthquake. Although the magnitude of the 1978 earthquake is larger than that of the 1983 Taipingshan earthquake, the focal depth of $161 \mathrm{~km}$ for the former seems not be able to reflect the above-mentioned precursors.

Acknowledgements. The authors are grateful to Prof. S. Miyamura for numerous valuable suggestions. Routine work on earthquake location and magnitude estimation by the staff of the TTSN is very much appreciated. This study was sponsored by Academia Sinica and the National Sciences Council, ROC under Grant No. NSC76-0202-M001-04.

\section{REFERENCES}

Chen, K.C. and J.H. Wang, 1984: On the study of 10 May, 1983 Taipingshan, Taiwan earthquake sequence. Bull. Inst. Earth Sci, Acad. Sin., ROC, 4, 1-28.

Engdahl, E.R. and C. Kisslinger, 1977: Seismological precursors to a magnitude 
5 earthquake in the Central Aleutian Islands. J. Phys. Earth, 25, 52435250 .

Gutenberg, B. and C.F. Richter, 1944: Frequency of earthquakes in California. Bull. Seism. Soc. Am., 34, 185-188.

Gutenberg, B. and C.F. Richter, 1956: Magnitude and energy of earthquakes. Ann. Geofis., 1.

Hasegawa, A., T. Hasagawa and T. Hori , 1975: Premonitory variation in seismic velocity related to the Southeastern Akita earthquake of 1970 . J. Phys. Earth, 23, 189-203.

Ishida, M. and M. htake, 1984: Seismicity and waveforms of microearthquakes before and after the Shizuoka-Seibu earthquake, central Japan. Bull. Seism. Soc. Am., 74, 605-620.

Li, Q.T., J.B. Chen, L.Yu and B.L. Hao, 1978: Time and space scanning of the b-value: A mathod for monitoring the development of catastrophic earthquakes. Acta Geophys. Sinica, 21, 101-125.

Kanamori, H. , 1981: The nature of seismicity patterns before earthquakes, Earthquake Prediction - An International Review. Maurice Ewing Series 4, AGU, 1-19.

McNally, K.C. , 1983: Seismic gaps in space and time. Ann. Rev. Earth Planet. Sci., 11, 359-369.

Miyamura, S. , 1962: Magnitude-frequency relation of earthquakes and its bearing on geotectonics. Proc. Japan Acad, 38, 27-30.

Mezcua, J., M. Herraiz and E. Buforn, 1984: Study of the 6 June Lorca (Spain) earthquake and its aftershock sequence. Bull. Seism. Soc. Am., 74, 167179.

Mogi, K., 1967: Earthquake and fracture. Tectonophys., 5, 35-55.

Mogi, K. , 1968: Some features of recent seismic activity in and near Japan, (1). Bull. Earthq. Res. Inst., Tokyo Univ., 46, 1225-1236.

Mogi, K. , 1979: Two kinds of seismic gaps. Pure Applied Geophys., 117, $1172-1186$.

MRSO , 1982: Final Report of SLAR Survey of the Republic of China, Mining Res. Service Organ., Indus. Tech. Res. Inst., Taipei, Taiwan, 84pp.

Ohtake, M., T. Matumoto and G.V. Latham , 1977a: Seismicity gap near Oaxaca, Southern Mexico as a probable precursor to a large earthquake. Pure Appl. Geophys., 115, 375-385.

Ohtake, M., T. Matumoto and G.V. Latham, 1977b: Temporal changes in seismicity preceding some shallow earthquakes in Mexico and Central America. Bull. Inter. Inst. Seism. Earthq. Eng., 15, 105-129.

Rikitake, T., 1979: Classification of earthquake precursors. Tectonophys., 54, 293-309. 
Sato, H. , 1977: Energy propagation including scattering effects: single isotropic scattering approximation. J. Phys. Earth., 25, 27-41.

Scholz, C.H. , 1968: The frequency-magnitude relation of microfracturing in rock and its relation to earthquakes. Bull. Seism. Soc. Am., 58, 399-415.

Tsai, Y.B., Z.S. Liaw, T.Q. Lee, M.T. Lin and H.L. Liu, 1977: Tectonic implications of the seismicity in the Taiwan region. Memoir Geol. Soc. China, 2, 13-41.

Tsai, Y.B., 1986: Seismotectonics of Taiwan. Tectonophys., 125, 17-37.

Wang, J.H. and K.C. Chen, 1985: The precursors of the 10 May, 1983 Taipingshan, Taiwan earthquake, Proceedings of the ROC- JAPAN Joint Seminar Multiple Hazards Mitigation, NTU, Taipei, Taiwan, ROC, 175-191.

Wang, J.H., Y.B. Tsai and K.C. Chen, 1986: Microfilming of Seismograms from the Taiwan Telemetered Seismographic Network. Bull. Inst. Earth Sci., Acad. Sin., ROC, 6, 227-234.

Wang, J.H. , 1988: Temporal change in duration ratios for foreshocks and aftershocks of a moderate Taiwan earthquake. Proc. Geol. Soc. China, 31, 99-110.

Wang, J.H., T.L. Teng and K.F. Ma, 1989: Temporal variation of coda Q during Hualien earthquake of 1986 in eastern Taiwan. Pure Appl. Geophys., 130, 617-634.

Wyss, M. and R.E. Habermann , 1979: Seismic quiescence precursory to a past and a future Kurile Island earthquakes. Pure Appl. Geophys., 117, $1195-1211$.

Wyss, M., F.W. Klein, and A.C. Johnston , 1981: Precursors to the Kalapana $\mathrm{M}=7.2$ earthquake. J. Geophys. Res., 86, 3881-3990.

Wyss, M., R.E. Habermann, and C. Heiniger, 1983: Seismic quiescence, stress drops, and asperities in the New Hebrides arc. Bull. Seism. Soc. Am. 73, 219-236.

Yeh, Y.T. and P.S. Hsu , 1983: Catalogue of earthquakes in Taiwan during 1901 to 1983. Inst. Earth Sci., Acad. Sin., ROC (unpublished). 


\title{
一個台灣中規模地震之前兆現象
}

\author{
陳國誠 王錦華* 葉王蓮 \\ 中央㸴究院地球科學研究所
}

一九八三年五月十日台灣宜闌太平山發生規模 $\mathrm{M}_{\mathrm{D}}=\mathbf{5 . 7}$ 之地震。在主震發生前之餘震 區呈現㜞低的地震活動。餘震的震央分布和未露出地面的斷層帶有相當的關係。另外由每月 地震發生频率, 可看出在餘震區及其鄰近地區存在異常的地震活動, 而且此異常的地震活動 是從震源區的外圍移至震源區。在主震發生約一年牛前, $\mathrm{b}$ 値增加而後遞減。在本文中同時 分析遠距離測站和近距離測站的地震尾波總振動時間之比値, 以爲研究地震前兆之指標, 此

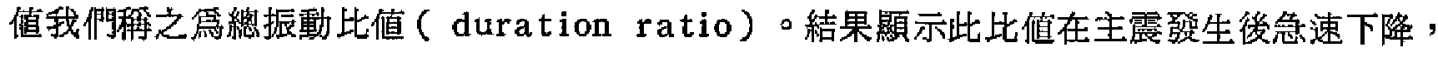
原因是所分析的地震資料均發生在一小的時間間隔中, 而高估了近距離測站的地震尾波之總 振動時間。但在主震發生 1 小時後, 振動比値上升, 此現象乃由於主震發生後, 地震規模 $M_{D}$ 大於 3 的地震個數急速增加, 形成較大的破碎密度所致。

$*$ 合聘於中央大學地球物理研究所 